\title{
Effect of Electrical Muscle Stimulation Belt for Abdominal Muscles Activation
}

\author{
Dayeong Choi ${ }^{a}$ and Won-Seob Shin ${ }^{b^{*}}$

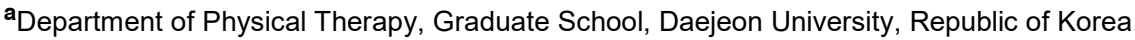 \\ ${ }^{b}$ Department of Physical Therapy, College of Health and Medical Science, Daejeon University, Republic of Korea
}

Objective: The purpose of this study is to observe the change in the thickness of abdominal muscles when electrical muscle stimulation (EMS) is applied to the abdomen during rest and abdominal muscle exercise to investigate the effect of EMS applied to the abdomen on the superficial and deep muscles thickness.

Design: Cross sectional design.

Methods: Twenty healthy subjects participated in this study. Subjects were performed resting position, resting position with EMS, curl-up and curl-up with EMS. The electrode of the EMS belt is attached to the abdominal wall between the 12th rib and iliac crest. The thickness of abdominal muscles including rectus abdominis (RA), external oblique (EO), internal oblique (IO), and transverse abdominis ( $\operatorname{TrA}$ ) were captured in each position by ultrasound image during expiration. All subjects were performed four positions randomly. Data were analyzed using repeated ANOVA with the level of significance set at $\alpha=0.05$.

Results: The muscle thickness of RA, EO, IO and TrA were significantly different at each position $(\mathrm{p}<0.05)$. The thickness of all abdominal muscles increased significantly when curl-up than curl-up with EMS. Both RA and EO thickness were significantly increased at resting position than resting position and EMS were combined $(\mathrm{p}<0.05)$. But IO and $\operatorname{TrA}$ thickness were decreased at resting position when EMS were combined.

Conclusions: The results suggest that EMS activates superficial abdominal muscles RA and EO. Therefore, abdominal strengthening exercise combined EMS can activate abdominal muscles and can be applied to various patients and rehabilitation in clinical practice.

Key Words: Electrical muscle stimulation, Abdominal stimulation, Abdominal muscles, Ultrasonography

서론

몸통근육은 표층 근육인 배곧은근, 배바깥빗근이 있으며 심부 근육으로는 배속빗근, 배가로근이 위치하고 있으며, 인체의 모든 힘과 운동성이 발생하는 곳으로 신체의 중심 을 잡아주고 근 골격구조를 적절히 유지시켜 준다[1,2]. 표층에 위치한 배곧은근과 배바깥빗근은 외력으로부터 장 기를 보호하고 외부에서 가해지는 힘에 대해 척추의 중립 위치를 유지해 준다[1,3]. 배속빗근과 배가로근은 몸통 안 정화에 기여하며, 특히 배가로근은 골반바닥근육과 함께 팔다리가 움직일 때 가장 먼저 수축해 서 있는 자세에서 몸통의 안정성에 관여해 자세를 유지시킨다[4,5]. 몸통 안
정화 근육의 약화는 허리 통증을 불러 일으켜 허리의 안 정을 유지하기 위해 몸통근육의 활성화는 필수적이다 $[4,6]$.

복부근육 강화 운동 방법으로는 플랭크운동(plank exercise), 옆으로 누운 자세에서 몸통 들어올리기 운동(side plank exercise), 몸통 들어올리기 운동(curl-up exercise) 등이 있고, 이러한 운동들에 도구를 이용해 복부근육을 더욱 활성화시킬 수 있다[7,8,9]. 여러 복부 운동 중 몸통 들어올리기 운동은 복부 근육을 강화시키고 흔하게 쓰이 고 있다[10]. 몸통 들어올리기 운동은 배곧은근을 활성화 시키면서 척추 하중을 감소해 복부근육 강화 운동 뿐만 아니라 허리 안정화 중재에도 쓰여왔다[12].

Received: Dec 1, 2021 Revised: Dec 17, 2021 Accepted: Dec 17, 2021

Corresponding author: Won-Seob Shin (ORCID https://orcid.org/0000-0002-6515-7020)

Department of Physical Therapy, Applied Science Building, 62, Daehak-ro, Dong-gu, Daejeon, 34520, Republic of Korea

Tel: +82-42-280-2294 Fax: +82-42-280-2295 E-mail: shinws@dju.kr

This is an Open-Access article distributed under the terms of the Creative Commons Attribution Non-Commercial License (http://creativecommons.org/licenses/ by-nc/4.0) which permits unrestricted non-commercial use, distribution, and reproduction in any medium, provided the original work is properly cited.

Copyright $(2021$ Korean Academy of Physical Therapy Rehabilitation Science 
전기근육자극(electrical muscle stimulation; EMS)은 지난 몇 년간 뼈대근육의 재교육과 근력 강화를 위해 사 용되어 왔다[13]. 선행연구 중 Coghlan 등[13] 의 연구에 서 복부에 $\mathrm{EMS}$ 를 적용한 결과 배가로근의 두께가 유의 하게 증가하였고, Kemmler 등[14]은 몸 전체에 $\mathrm{EMS}$ 를 적용한 결과 팔다리의 골격격근량이 증가하였고 체지방은 감소했다고 보고했다. 또한 $\operatorname{Han}$ 등[15]의 연구에서는 스 쿼트 동작에 $\mathrm{EMS}$ 를 동시에 적용한 결과 민첩성과 지구 력이 증가하고 중간넓은근, 넙다리곧은근, 배곧은근, 배바 깥빗근과 배안쪽빗근의 두께가 증가했다고 보고하였고, Vitzel 등[16]은 24명의 대상자에게 5일동안 운동과 EMS 를 적용한 결과 근력이 $58 \%$, 지구력이 $100 \%$ 증가하고 허리둘레가 $3.5 \mathrm{~cm}$ 감소했다고 하였다.

선행 연구에서 $\mathrm{EMS}$ 와 다양한 중재를 같이 적용한 결 과 표층에 위치한 배곧은근부터 가장 심부에 있는 배가로 근까지 두께의 변화가 있는 것이 확인되었다. 그러나 복 부근육의 두께 증가가 $\mathrm{EMS}$ 의 효과 때문인지, 오직 운동 의 효과 때문인지 알 수 없었다. 또한 대부분의 연구들은 복부 운동과 $\mathrm{EMS}$ 를 같이 적용해 복부 근육의 두께 변화 에 초점을 맞춰져 있다. 그러나 표층 근육과 심부 근육 중 어떤 근육이 더욱 더 활성화 되는지 또는 안정 시와 운동 시 각각의 자세에서 $\mathrm{EMS}$ 를 적용 유무에 따라 복부 근육 들의 두께 변화를 비교하는 연구는 부족한 실정이다. 따 라서 본 연구의 목적은 안정 시와 복부 근육 운동 시 복 부에 $\mathrm{EMS}$ 를 적용하였을 때 복부근육의 두께 변화를 관 찰해 복부에 적용하는 $\mathrm{EMS}$ 가 표층 근육과 심층 근육에 미치는 영향을 알아보고자 한다.

\section{연구 방법}

\section{연구 대상}

본 연구의 대상자는 대전광역시에 위치한 $\mathrm{D}$ 대학교에 재학중인 건강한 20 30대 남녀를 20명을 대상으로 선정 하였다. 대상자의 선정 조건은 다음과 같다. 첫째, 체질량 지수(body mass index; BMI)가 $18.5 \sim 30 \mathrm{Kg} / \mathrm{m}^{2}$ 에 해당 하는 자, 둘째, 전반적인 건강 상태가 좋은 자로 선정 하 였다[13]. 제외 조건은 다음과 같다. 첫째, 최근 6 개월 이 내에 허리통증을 경험한 자, 둘째, 지난 6개월 동안 규칙 적인 복부 근육 운동을 한 자, 셋째, 심장 박동기(cardiac peacemaker)를 이식한 자, 넷째, 임신을 한 자는 제외하 였다[16]. 본 연구의 모든 대상자들은 연구에 대한 설명을 듣고 충분한 이해를 하였으며, 자발적으로 실험 참가서에 동의하고 서명한 자만 대상으로 하였다.

\section{평가 도구 및 방법}

복부 근육에 전기 자극을 주기 위해 EMS 운동보조벨 트(코어킹허리벨트, 미호비즈텍, Korea)을 사용하였다. EMS 벨트는 2 개의 전극 패드가 있으며, 복벽의 앞과 양 옆 부 분에 자극이 오도록 12 번째 갈비뼈(12th ribs)와 엉덩뼈 능선(illiac crest)사이에 오게 위치하였다. EMS의 강도는 편한 강도로 느끼되, 복부 근육이 수축되는 느낌이 들 때 까지 스스로 자극 조절하게 하였다[13]. EMS자극과 동시 에 초음파 관찰을 하기 위해 전극 패드 사이와 위, 아래에 있는 실리콘은 제거하였다.

측정 자세는 총 네 가지 자세를 측정하였다. 대상자들은 바로 누운 자세에서 무릎을 $45^{\circ}$ 정도 굽힌 자세(hook-lying position)를 기본 자세로 설정하고 이 자세에서 McGill의 몸통 들어올리기(curl-up)를 실시한 동작과 이 두 가지 자 세에서 각각 전기 자극 패드가 부착된 $\mathrm{EMS}$ 를 착용하고 수행하도록 하였다[11,17]. 네 가지 측정 순서는 무작위로 시행하였다.

\section{측정 도구 및 방법}

대상자에 대한 $\mathrm{EMS}$ 적용 전·후 배곧은근, 배바깥빗근, 배안쪽빗근, 배가로근의 수축을 확인하고 두께를 관찰하 기 위하여 진단용 초음파 기구(Dual-MicrUs EXT-1H; Telemed, Vilnius, Lithuania)를 사용하였다.

대상자의 네 가지 복부 근육의 두께를 측정하기 위해 바로 누운 자세에서 무릎을 $45^{\circ}$ 정도 굽힌 자세를 취하도 록 하였다[17]. 그리고 대상자에게 편안한 호흡을 실시하 라고 하였고 1회 호흡량(tidal volume)의 호기(expiration) 시점에 촬영하였다[18]. 이 자세에서 배곧은근의 두께를 측정하기 위해 표층 밑 근육 전용인 직선형 탐촉자를 이 용하였고, 영상 촬영은 $\mathrm{B}$ (brightness) mode 에서 주파수 는 $5 \mathrm{MHz}$ 로 고정하였으며 탐촉자의 위치는 배꼽을 기준 으로 우측 가쪽으로 $1 \mathrm{~cm}$, 밑으로 $2 \mathrm{~cm}$ 되는 부분이다 [19]. 일정하게 측정하기 위해 배곧은근의 근막선이 화면 에서 일직선을 유지할 수 있도록 조절하였다[20]. 배바깥 빗근과 배안쪽빗근, 배가로근의 두께는 곡선형 탐촉자를 이용하였고, $\mathrm{B}$ mode에서 주파수는 $2 \mathrm{MHz}$ 로 고정하였다. 탐촉자는 우측 체간 측면의 겨드랑이선을 중심으로 12 번 째 갈비뼈와 엉덩뼈 능선 중간 지점에서 전방으로 $2.5 \mathrm{~cm}$ 부위에 탐촉자의 중앙이 닿도록 위치 시켰다[21].

근육의 두께 측정은 Image $\mathrm{J}($ National Institutes of Health, USA) 프로그램을 통해 측정했다. 배곧은근의 두 께는 상하 고반향성 근막(superior and inferior hyperechoic muscle fascias) 사이의 거리를 수직으로 측정하였다[22]. 배가로근, 배속빗근, 배바깥빗근의 경우 배가로근과 등허 리근막(thoracolumbar fascia)이 만나는 근막 접합부위 
(the muscle-fascia junction)에서 $1.5 \mathrm{~cm}$ 떨어진 부위에 수평선을 그어 수직이 되는 부위에서 상하 고반향성 근막 (superior and inferior hyperechoic muscle fascias) 사이 의 거리로 두께를 측정하였다[23]. 모든 측정은 한 명의 치료사가 충분한 연습을 거친 뒤 측정하였으며 측정 부위 는 펜으로 표시해 탐촉자가 같은 위치를 유지하게 하였고, 대상자 마다 오른쪽을 3 번씩 측정해 평균값을 사용하였 다. 근 피로도를 최소화 하기 위해 한 자세 측정 뒤 3 분간 의 휴식시간을 갖도록 하였다[24].

\section{분석 방법}

본 연구를 통해 수집된 자료는 IBM SPSS(SPSS ver. 25.0, IBM Co., USA)를 사용하여 통계분석을 실시하였 다. $\mathrm{EMS}$ 적용 전·후 변화되는 복부 근육 두께의 차이를 비교하기 위해 repeated measure ANOVA을 통해 분석 하였으며 자세별 차이를 알아보기 위해 사후검정은 본페 로니 검정(Bonferroni test)을 실시하였다. 모든 통계 분석 에서 유의수준 $(\alpha)$ 은 0.05 로 하였다.

\section{연구 결과}

\section{연구 대상자의 일반적 특성}

본 연구에 참여한 대상자들의 일반적 특성은 다음과 같 다(Table 1).

\section{운동자세별 복부근육활성도 비교}

본 연구 결과는 다음과 같다(Table 2). 배곧은근, 배바 깟빗근, 배안쪽빗근 그리고 배가로근 모두네 가지 측정 자세에서 유의한 차이를 보였다 $(\mathrm{p}<0.05)$ (Table 2).

사후분석 결과 배곧은근은 기본자세보다 나머지 세 자 세가 유의하게 컸다 $(\mathrm{p}<0.05)$. 그리고 기본자세, 기본자 세에 EMS자극, 몸통 들어올리기, 몸통 들어올리며 EMS 자극 순으로 각각 유의하게 큰 것으로 나타났다 $(\mathrm{p}$ $<0.05)$. 배바깥빗근은 기본자세, 몸통 들어올리기, 기본 자세에 EMS자극, 몸통 들어올리며 EMS자극 순으로 컸 다. 그러나 몸통 들어올리기 자세와 기본자세에서 EMS 자극시 유의한 차이는 없었다. 배안쪽빗근의 두께는 기 본자세에 EMS적용, 기본자세, 몸통 들어올리기 동작, 몸 통 들어올리면서 $\mathrm{EMS}$ 적용 순으로 컸다. 사후분석 결과 기본자세와 기본자세에서 EMS자극에서 유의한 차이가 없었고, 또한 몸통 들어올리기 동작과 몸통 들어올리며 EMS자극에서 유의한 차이가 없었다. 배가로근은 기본자 세에 $\mathrm{EMS}$ 적용, 기본자세, 몸통 들어올리기, 몸통 들어올 리면서 EMS자극 순으로 컸다. 사후분석 결과 몸통 들어 올리기 동작과 나머지 세 동작에서 유의한 차이를 보였 다 $(\mathrm{p}<0.05)$. 그러나 기본자세와 기본자세에서 $\mathrm{EMS}$ 자 극, 몸통 들어올리기 동작에서 유의한 차이는 없었다 (Table 2).

Table 1. The general characteristics of the subjects

$(\mathrm{N}=20)$

\begin{tabular}{llll}
\hline & Male $(\mathbf{n}=\mathbf{9})$ & Female $(\mathbf{n}=\mathbf{1 1})$ & Total $(\mathbf{N}=\mathbf{2 0})$ \\
\hline Age $($ year $)$ & $22.78 \pm 3.60$ & $21.09 \pm 1.04$ & $21.85 \pm 2.60$ \\
Height $(\mathrm{cm})$ & $174.39 \pm 4.59$ & $161.40 \pm 3.91$ & $167.25 \pm 7.80$ \\
Weight $(\mathrm{kg})$ & $68.72 \pm 8.05$ & $58.68 \pm 6.67$ & $63.20 \pm 8.77$ \\
Body mass index $\left(\mathrm{Kg} / \mathrm{m}^{2}\right)$ & $22.67 \pm 3.16$ & $22.50 \pm 2.19$ & $22.58 \pm 2.60$ \\
\hline
\end{tabular}

Values are presented mean $\pm \mathrm{SD}$

Table 2. Changes in the thickness of the abdominal muscles by postures

$(\mathrm{N}=20)$

\begin{tabular}{lllllll}
\hline & Rest $^{\mathbf{a}}$ & Curl-up $^{\mathbf{b}}$ & Rest + EMS $^{\mathbf{c}}$ & Curl-up+EMS $^{\mathbf{d}}$ & $\mathbf{F}(\mathbf{p})$ & post-hoc \\
\hline $\mathrm{RA}(\mathrm{mm})$ & $10.22 \pm 2.37$ & $13.18 \pm 3.10$ & $11.81 \pm 3.19$ & $14.77 \pm 4.04$ & $38.132(0.000)$ & $\mathrm{a}<\mathrm{c}<\mathrm{b}<\mathrm{d}$ \\
$\mathrm{EO}(\mathrm{mm})$ & $5.48 \pm 1.69$ & $6.36 \pm 2.03$ & $6.28 \pm 1.98$ & $7.22 \pm 1.99$ & $15.644(0.000)$ & $\mathrm{a}<\mathrm{bc}<\mathrm{d}$ \\
$\mathrm{IO}(\mathrm{mm})$ & $7.04 \pm 1.93$ & $8.42 \pm 2.85$ & $6.99 \pm 2.08$ & $8.64 \pm 2.88$ & $5.331(0.009)$ & $\mathrm{ac}<\mathrm{bd}$ \\
$\operatorname{TrA}(\mathrm{mm})$ & $2.85 \pm 0.57$ & $3.14 \pm 0.77$ & $2.82 \pm 0.53$ & $3.21 \pm 0.57$ & $4.326(0.019)$ & $\mathrm{abc}<\mathrm{d}$ \\
\hline
\end{tabular}

RA : rectus abdominis, EO : external oblique, IO : internal oblique, TrA : transverse abdominis.

Values are presented mean \pm SD 


\section{고찰}

몸통 근육 강화 운동과 $\mathrm{EMS}$ 를 같이 적용해 복부 근육 의 활성화와 두께 변화 등을 알아보는 다양한 연구들이 진행되어 왔다. 대부분의 연구들은 복부 운동과 $\mathrm{EMS}$ 를 같이 적용해 복부 근육의 두께 변화에 초점을 맞추어져 있으나 어떤 근육군이 더욱 더 활성화 되는지 또는 복부 근육들에 자세와 EMS자극 유무에 따른 각각의 두께 변 화 비교 연구는 부족한 실정이다. 따라서 본 연구는 안정 시와 몸통 들어올리기 동작 수행 시 복부에 $\mathrm{EMS}$ 를 적용 하였을 때 총 네 가지 자세에서 배곧은근, 배바깥빗근, 배 안쪽빗근 그리고 배가로근의 두께의 변화를 초음파를 통 해 알아보고자 하였다.

본 연구의 결과 배곧은근과 배바깥빗근의 두께가 네 가 지 자세에서 모두 유의하게 차이가 났고 안정 시와 몸통 들어올리기 동작을 수행할 때 EMS자극 전과 후에 유의 하게 커졌다. 본 연구에서 쓰인 EMS허리 벨트는 단계가 $1 \sim 20$ 단계로 구성되어 있고, 주파수는 $1 \sim 100 \mathrm{~Hz}$ 사이다. 대부분의 대상자들이 $1 \sim 5$ 단계로 낮은 주파수에서 자극 을 받았다. 따라서 $\mathrm{EMG}$ 를 복부에 적용했을 시 표층 근 육에 더 자극을 전달했다고 본다. 본 연구에서 실행한 몸 통 들어올리기 동작은 McGill[12]의 연구에서 근전도 (electromyography; EMG) 결과 심부 근육인 배안쪽빗근 과 배가로근보다 배곧은근과 허리근(psoas)이 더 활성화 되었다고 밝혀냈다. 따라서 본 연구에서 배곧은근이 배안 쪽빗근과 배가로근보다 몸통 들어올리기 동작 수행 시 $\mathrm{EMG}$ 자극 전 후 두께 차이가 유의하게 차이가 났을 것이 라고 사료된다.

반면에 배안쪽빗근과 배가로근은 몸통 들어올리기 동 작을 할 때 $\mathrm{EMS}$ 적용 전과 후 유의하게 두께가 커졌지만, 안정시 자세에서 $\mathrm{EMS}$ 적용 전과 후 유의한 차이가 없었 다. 이는 $\mathrm{EMS}$ 가 심부 근육까지 영향을 끼치지 못했다고 생각된다. 배가로근을 활성화 시키는 할로잉(hollowing) 기법 또는 복부 드로잉-인 기법(abdominal drawing-in maneuver)을 적용한 결과 초음파 영상에서 배가로근의 두께가 증가한 것을 볼 수 있었다 $[19,20,25]$. 따라서 심 부 근육인 배가로근을 활성화시켜 몸통 안정화 훈련을 하 고자 할 때는 $\mathrm{EMS}$ 보다는 배가로근을 개별적으로 활성화 시키는 운동 방법이 더 중요하다고 생각된다.

본 연구에서는 20 대 건강한 일반인을 대상으로 하였다. 그러나 선행연구들중 허리통증, 뇌졸중 환자, 척수손상 환 자 등을 대상으로 한 다양한 연구들이 있다. 뇌졸중 환자 를 대상으로 진행한 연구 중 Jung 등[26]의 연구에서 18 명의 만성 뇌졸중 환자에게 복부에 $\mathrm{EMS}$ 와 흡기근 (inspiratory muscle) 훈련을 같이 적용한 결과 마비측 가 로막이 유의하게 두꺼워졌다. 또한 Park 등[27]은 뇌졸중
환자의 복부와 허리에 $\mathrm{EMS}$ 를 적용하고 코어운동을 병행 한 결과 균형능력이 유의하게 향상되었다고 보고했다. $\mathrm{Kim}$ 등[28]은 만성 뇌졸중 환자에게 $\mathrm{EMS}$ 를 적용하면서 계단 보행 훈련을 한 결과 환자들의 하지 근력이 향상했 다. 또한 $\mathrm{EMS}$ 는 척수손상 환자의 재활에도 다양하게 활 용되고 있는 추세이다. Edwin Langbein 등[29]은 손상학 적 수준이 C5-T7인 척수손상 환자의 복부에 $\mathrm{EMS}$ 를 적 용하고 폐기능 검사를 실시하였다. 그 결과 노력성폐활량 (forced vital capacity; FVC), 1초간 노력성 페활량 (forced expiratory flow in 1s; FEV1) 그리고 최대날숨 유속(peak expiratory flow rate; $\mathrm{PEF}$ )이 유의하게 향상했 다. $\mathrm{McBain}$ 등[30]은 복부 근육에 $\mathrm{EMS}$ 를 적용한 기침 훈련이 척수손상 환자들의 기침능력 향상에 효과가 있다 고 하였다. $\mathrm{Kim}$ 등[31]의 연구에서 퇴행성 허리 뒤굽음증 환자에게 복부와 허리에 $\mathrm{EMS}$ 를 적용해 초음파로 배바깥 빗근, 배안쪽빗근 그리고 배가로근과 허리부분의 뭇갈래 근(lumbar multifidus)의 두께를 관찰한 결과 위의 네 가 지 근육들의 두께가 두꺼워진 것을 볼 수 있었다.

이처럼 $\mathrm{EMS}$ 는 일반인과 근골격계 또는 신경계 환자 등 다양한 상황에 적용할 수 있어 임상적 의의가 크다.

본 연구의 제한점은 다음과 같다. 첫째, 실험 대상자가 20 대 건강한 남녀에 국한되어 있고 참가 인원은 20 명으 로 대상자의 수가 적어 일반화시키기 어렵다. 둘째, 여러 가지 복부강화 운동이 있음에도 불구하고 주로 배곧은근 이 활성화되는 몸통 들어올리기 자세를 선택했기 때문에 심부 근육에도 영향을 미치지 못하였다. 셋째, 일반인을 대상으로 했기 때문에 다양한 질환의 특성을 고려하지 못 하였다. 따라서 향후에 환자군을 대상으로 다양한 복부 근육 강화 운동에 $\mathrm{EMS}$ 를 적용해 복부 근육의 두께와 활 성도를 보는 연구를 할 것을 제안한다.

\section{References}

1. Park J, Jeong J. Effects of Plank Exercises with Resistance of One-Sided Hip Adduction on the Abdominal Muscle Thickness. J Kor Phys Ther. 2019;31:82-7.

2. Lee H, Lee J, Tae K. The Effects of Low-Frequency Electrical Stimulation on Abdominal Core Muscle Activity and Thickness. Journal of Rehabilitation Welfare Engineering \& Assistive Technology 2013;7:85-90.

3. Lee H. Activation of Trunk Muscles during Stabilization Exercises in Four-point Kneeling. J Kor Phys Ther 2010;22:33-8.

4. Kim JS, Choi JD, Shin WS. Effect of different contraction methods on pelvic floor muscle contraction 
in middle-aged women. Phys Ther Rehabil Sci 2015; 4:103-7.

5. Neumann P, Gill V. Pelvic Floor and Abdominal Muscle Interaction: EMG Activity and Intra-abdominal Pressure. Int Urogynecol J 2002;13:125-32.

6. Choi HS, Shim YJ, Shin WS. Comparison on postural control between abdominal draw-in maneuver and abdominal expansion maneuver in persons with stroke. Phys Ther Rehabil Sci 2016;5:113-9.

7. Stevens VK, Bouche KG, Mahieu NN, Coorevits PL, Vanderstraeten GG, Danneels LA. Trunk muscle activity in healthy subjects during bridging stabilization exercises. BMC Musculoskelet Disord 2006;7:1-8.

8. Lehman GH, Hoda W, Oliver S. Trunk muscle activity during bridging exercises on and off a Swissball. Chiropr Osteopat 2005;13:1-8.

9. Takemasa R, Yamamoto H, Tani T. Trunk Muscle Strength in and Effect of Trunk Muscle Exercises for Patients With Chronic Low Back Pain. Spine 1995;20:2522-30

10. Clark KM, Holt LE, Sinyard J. Electromyographic comparison of the upper and lower rectus abdominis during abdominal exercises. J Strength Cond Res 2003;17(3):475-83.

11. McGill SM. Low back exercises: Evidence for improving exercise regimens. Physical therapy 1998; 78(7):754-65.

12. Yoo SA, Yoo KU, Lim CH, Kim CY, Kim HD. Effects of Neuromuscular Electrical Stimulation Training on Abdominal Fat, Trunk Muscle Thickness and Activity in Middle-Aged Women with Abdominal Obesity. J Korean Soc Phys Med 2019;14(2):125-35.

13. Coghlan S, Crowe L, McCarthyPerssonU, Minogue C, Caulfield B. Electrical muscle stimulation for deep stabilizing muscles in abdominal wall. 2008 30th Annual International Conference of the IEEE Engineering in Medicine and Biology Society 2008:2756-9.

14. Kemmler W, Stengel S von. Whole-body electromyostimulation as a means to impact muscle mass and abdominal body fat in lean, sedentary, older female adults: Subanalysis of the TEST-III trial. Clin Interv Aging 2013;8:1353-64.

15. Han HI, Jeong YJ, Sin HY, Lee DY, Hong JH, Kim JS, Yu JH. Effects of Squats Exercise with
EMS on Muscle Strength, Endurance, and Body Function. Bio-inspired Neurocomputing 2020;903:259-71.

16. Vitzel KF, Fortes MA, Marzuca-Nassr GN, Servino VM, Pinheiro $\mathrm{CH}$, Silveira LR, Curi R. In vivo electrical stimulation for the assessment of skeletal muscle contractile function in murine models. Methods Mol Biol 2018;1735:381-95.

17. Kiesel KB, Underwood FB, Matacolla C, Nitz AJ, Malone TR. A comparison of select trunk muscle thickness change between subjects with low back pain classified in the treatment-based classification system and asymptomatic controls. J Orthop Sports Phys Ther 2007;37(10):596-607.

18. Whittaker JL. Ultrasound imaging of the lateral abdominal wall muscles in individuals with lumbopelvic pain and signs of concurrent hypocapnia. Man Ther 2008;13(5):404-10.

19. Ha Y, Lee GC, Bae WS, Cho YJ. The Effect of Abdominal Muscle Drawing-In Exercise During Bridge Exercise on Abdominal Muscle Thickness, using for Real-time Ultrasound Imaging. J Korean Soc Phys Med 2013;8(2):231-8.

20. Lee S, Han S, Lee D. Comparison of abdominal muscle thickness according to feedback method used during abdominal hollowing exercise. J Phys Ther Sci 2016;28(9):2519-21.

21. Mangum LC, Henderson K, Murray KP, Saliba SA. Ultrasound assessment of the transverse abdominis during functional movement. J Ultrasound Med 2018;37(5):1225-31.

22. Coldron Y, Stokes MJ, Newham DJ, Cook K. Postpartum characteristics of rectus abdominis on ultrasound imaging. Man Ther 2008;13(2):112-21.

23. Hodges PW, Pengel LHM, Herbert RD, Gandevia SC. Measurement of muscle contraction with ultrasound imaging. Muscle Nerve 2003;27(6):682-92

24. Ota M, Kaneoka K. Differences in abdominal muscle thicknesses between chronic low back pain patients and healthy subjects. J Phys Ther Sci 2011; 23(6):855-8.

25. Hosseinifar M, Akbari M, Behtash H, Amiri M, Sarrafzadeh J. The effects of stabilization and Mckenzie exercises on transverse abdominis and multifidus muscle thickness, pain, and disability: A randomized controlled trial in nonspecific chronic low back pain. J Phys Ther Sci 2013;25(12):1541-5. 
26. Jung JH, Shim JM, Kwon HY, Kim HR, Kim BI. Effects of abdominal stimulation during inspiratory muscle training on respiratory function of chronic stroke patients. J Phys Ther Sci 2014;26(1):73-6.

27. Park M, Seok H, Kim SH, Noh K, Lee SY. Comparison between neuromuscular electrical stimulation to abdominal and back muscles on postural balance in post-stroke hemiplegic patients. Ann Rehabil Med 2018;42(5):652-9.

28. Kim D, An H, Choi W, Park S, Kim S. Effect of Functional Electrical Stimulation on Balance and Gait in Patients with Subacute Stroke. J Int Acad Phys Ther Res 2021;12(3):2393-402.

29. Langbein WE, Maloney C, Kandare F, Stani U, Nemchausky B, Jaeger RJ. Pulmonary function testing in spinal cord injury: Effects of abdominal muscle stimulation. J Rehabil Res Dev 2001;38(5):591-7.

30. McBain RA, Boswell-Ruys CL, Lee BB, Gandevia $\mathrm{SC}$, Butler JE. Abdominal muscle training can enhance cough after spinal cord injury. Neurorehabil Neural Repair 2013;27(9):834-43.

31. Kim SY, Kim JH, Jung GS, Baek SO, Jones R, Ahn SH. The effects of transcutaneous neuromuscular electrical stimulation on the activation of deep lumbar stabilizing muscles of patients with lumbar degenerative kyphosis. J Phys Ther Sci 2016;28(2): 399-406. 